Aim of the study: Lung cancer is the most common malignancy, accounting for one-third of all deaths from cancer. Some studies have shown that low molecular weight heparin (LMWH) significantly prolongs the survival of patients with non-small cell lung cancer (NSCLC).

The aim of this study was to determine the effects of treating inoperable stage III NSCLC with LMWH in addition to concurrent chemoradiotherapy.

Material and methods: Eighty-two patients with inoperable stage III NSCLC were evaluated at Dicle University's Medical Oncology Department between 2005 and 2010. All patients were treated with concurrent chemoradiotherapy (CRT) with or without LMWH (enoxaparin 4000 IU/day) depending on the patient's risk of thrombosis. The primary objectives were to determine disease-free survival (DFS) and overall survival (OS) for patients treated with $\mathrm{LMWH}$.

Results: A total of 38 patients in the LMWH negative group and 44 patients in the LMWH positive group were included in the study. The median OS was 11.2 months for the enoxaparin recipients and 12.7 months for the non-enoxaparin group $(p=0.4)$. The median DFS was 9.3 months with CRT alone and 10.0 months with CRT plus enoxaparin $(p=0.9)$. The one-year OS rates were $47 \%$ and $34 \%$ for groups treated with CRT and enoxaparin plus CRT, respectively, while the two-year OS rates were $23 \%$ and $21 \%$, respectively. No significant difference was noted between the two groups in terms of grade 3-4 hematologic toxicity and mucositis $(p=0.3)$.

Conclusions: This study did not demonstrate improvements in survival for patients with NSCLC treated with enoxaparin. LMWH's positive contribution is still controversial.

Key words: non-small cell lung cancer, low molecular weight heparin, chemoradiotherapy.

\section{Can LMWH improve the outcome of patients with inoperable stage III non-small cell lung cancer?}

\author{
Mehmet Kucukoner, Abdurrahman Isikdogan, Muhammed Ali Kaplan, \\ Ali Inal, Seyit Burhanedtin Zincircioglu, Murtaza Cit, Timucin Cil, \\ Bilgehan Karadayi, Ahmet Dirier, Ismail Yildiz
}

Dicle University, Adana Numune Hospital, Ministry of Health of Turkey

\section{Introduction}

Lung cancer is one of the most common cancers and a major cause of cancer-related mortality worldwide. Non-small cell lung cancer (NSCLC) comprises $85 \%$ of all lung cancers [1]. Stage IIIA and IIIB lung cancers include patients with locally advanced disease and without distant metastases [2]. Five-year survival rates for stage IIIA and IIIB NSCLC treated with standard concurrent chemoradiotherapy (CRT) are 19\% and 7\%, respectively, and the median survival times are 22 and 13 months, respectively. In the past, the standard treatment for NSCLC was radiotherapy or surgery, alone, which provided a median survival of approximately 10 months [3]. CRT is now the standard treatment [4].

Thromboembolism is the most common complication in patients with cancer. Cancer has been identified as an independent risk factor for the development of venous thromboembolism (VTE) [5]. Activation of the coagulation system occurs frequently in patients with cancer. Recent studies have shown that the pathogenesis of thromboembolism in malignancy is associated with the hemostatic alterations induced by cancer cells, the activation of blood coagulation and the inhibition of anticoagulant function. Although thromboembolism is commonly observed in patients with advanced cancer, it may occur in patients with occult cancer [6].

Anticoagulants may, therefore, have an important role in treating the thromboembolic complications of cancer and preventing their recurrence [6]. VTE in cancer patients is treated with LMWH or, less commonly, unfractionated heparin, whereas oral anticoagulants, principally warfarin, are commonly used for long-term prophylaxis [7]. Anticoagulation therapy decreases the incidence of VTE in patients with cancer [5]. Heparins have been reported to interfere with tumor progression and, in particular, with the occurrence and development of metastases in laboratory animals [8, 9]. The positive effects of LMWH on disease-free survival and overall survival have been shown in some different cancer studies $[5,10,11]$. However, in studies of patients with NSCLC, this positive response has not been observed $[12,13]$. The potential survival benefits of heparin therapy for patients with cancer need to be evaluated in further clinical research. There are not adequate studies on the effect of LMWH on the survival of patients with NSCLC.

In our clinic, we detected a decreased risk of thrombosis in patients who were given LMWH prophylaxis, and these patients had good clinical courses. The goal of this study was to determine whether the addition of LMWH to CRT would improve NSCLC patient outcomes compared with CRT alone. There is no conflict of interest between the authors. 


\section{Material and methods}

\section{Patients}

Patients diagnosed with NSCLC who presented to the Radiation and Medical Oncology Department of Dicle University Medicine Faculty between January 2005 and October 2010 were included in the study. All patients in this study had histologically confirmed medically inoperable or unresectable stage IIIA and IIIB NSCLC. Each patient had an Eastern Cooperative Oncology Group (ECOG) performance status (PS) of less than two and normal hematological, renal and hepatic function tests. Data were collected retrospectively from patient files. The patients' age, sex, stage, histological subtypes, performance status, and treatment responses were reviewed, and patients treated with $\mathrm{LMWH}$ due to risk of thrombosis were analyzed. The time periods from the diagnosis to progression and to death were recorded. Diseasefree survival (DFS) and overall survival (OS) and treatment toxicities were compared.

\section{Treatment regimen}

In this study, 82 patients were treated with concurrent CRT. As a clinical practice, patients with a risk factor for thrombosis (cancer, old age, impaired mobility, and/or cardiac and pulmonary diseases) were given LMWH [14]. The patients were divided into two groups: patients treated with concurrent CRT (60 Gy RT in 30 fractions plus weekly docetaxel $25 \mathrm{mg} / \mathrm{m}^{2}$ and cisplatin $25 \mathrm{mg} / \mathrm{m}^{2} ; n=38$ ) and patients treated with low molecular weight heparin (enoxaparin $4000 \mathrm{IU} /$ day) in addition to concurrent CRT $(n=44)$. When hemoptysis and other hemorrhages into organs were seen, the LMWH was stopped. If a partial response or stable disease response was observed in patients who received concurrent CRT, four additional cycles of chemotherapy were administered. Treatment toxicities were assessed according to the National Cancer Institute $(\mathrm{NCl})$ guidelines [15]. All patients received conventional fractionated external radiotherapy (2D) five days a week (from Monday to Friday), for a total dose of $60 \mathrm{~Gy}$ in $30 \mathrm{frac}-$ tions (2 Gy per day) administered over six weeks. A Simulix Oldef HP model simulator (Nucletron) was used to perform conventional simulation. For treatment of patients, a $6 \mathrm{MV}$ photon beam was used with an Alcyone II model Co60 (General Electric) radioactive source teletherapy machine or a Saturn 43 F model Linear Accelerator (General Electric).

\section{Statistical analysis}

DFS was accepted as the period from the date of diagnosis to progression or recurrence and OS was accepted as the period from the date of diagnosis to death. Statistical analyses were carried out using SPSS 11.5 software. Fisher's test and the independent samples test were used to compare the groups. Survival analyses were completed according to the Kaplan-Meier method with two-sided log rank statistics.

\section{Results}

A total of 82 patients were included in the study. Thirtyeight patients were in the LMWH negative group and 44 patients were in the $\mathrm{LMWH}$ positive group. The median age was 60 years (range 28-79). Of the patients, 4 were female
(4.9\%) and 78 were male (95.1\%). Statistical analysis showed no significant difference between the two groups in terms of age, gender, pathologic type or stage $(p>0.05)$. Patient characteristics are summarized in Table 1. Thirtyfour patients (42\%) had stage IIIA NSCLC, and 47 patients (58\%) had stage IIIB. During this study, 67 (81.7\%) of the 82 patients died from their disease, and the remaining 15 patients are still alive at the time of writing.

Median follow-up time was 12.5 months (range 1.1-87.3 months). Evaluation of survival results showed that the median DFS was 9.3 months for the enoxaparin negative group (95\% Cl: 7.4-11.2) and 10.0 months for the enoxaparin positive group (95\% Cl: 5.8-14.2; $p=0.9$ ) (Fig. 1A). The median OS was 12.7 months in the enoxaparin negative group (95\% $\mathrm{Cl}: 7.4-18.0)$ and 11.2 months in the enoxaparin positive group (95\% Cl: 7.1-15.3; $p=0.4$ ) (Fig. 1B). One- and two-year overall survival rates were $47 \%$ and $23 \%(n=38)$, respectively, for the enoxaparin negative group, and 34\% and $21 \%$ $(n=38)$, respectively, for the enoxaparin positive group $(n=44)$. The one- and two-year DFS rates were $37 \%$ and $15 \%$, respectively, and the median survival was 9.3 months (95\% Cl: 7.4-11.2) for patients treated with CRT alone. The one- and two-year DFS rates were $32 \%$ and $12 \%$, respectively, and the median survival was 10.0 months ( $95 \% \mathrm{Cl}$ : 5.8-14.2) for patients treated with CRT plus LMWH. These differences between treatment groups were not statistically significant $(p=0.9)$. The one- and two-year OS rates were $47 \%$ and $23 \%$, respectively, and the median survival time was 12.7 months (95\% Cl: 7.4-18.0) for patients treated with CRT alone. The one- and two-year OS rates were $34 \%$ and $21 \%$, respectively, and the median survival time was 11.2 months (95\% Cl: 7.1-15.3) for patients treated with CRT plus LMWH $(p=0.4)$. These results are summarized in Table 2 and Fig. 1. Overall tumor response rates were $88.5 \%$ with CRT alone $(n=35)$ and $82 \%$ with CRT plus LMWH $(n=39)(p=0.001)$.

Table 1. Characteristics of patients

\begin{tabular}{|c|c|c|c|}
\hline Characteristic & CRT $n(\%)$ & $\begin{array}{c}\text { CRT } \\
+ \text { LMWH } n(\%)\end{array}$ & $P$ value \\
\hline Median age (range) & $60(28-77)$ & $63(40-79)$ & 0.05 \\
\hline $\begin{array}{l}\text { Sex } \\
\text { male } \\
\text { female }\end{array}$ & $\begin{array}{c}35(92.1) \\
3(7.9)\end{array}$ & $\begin{array}{c}43(95.1) \\
1(4.9)\end{array}$ & 0.1 \\
\hline $\begin{array}{l}\text { Pathologic type } \\
\text { squamous } \\
\text { adenocarcinoma } \\
\text { non-subtype }\end{array}$ & $\begin{array}{c}14(38.9) \\
7(19.4) \\
15(41.7)\end{array}$ & $\begin{array}{c}21(50.0) \\
5(11.9) \\
16(38.1)\end{array}$ & 0.1 \\
\hline $\begin{array}{r}\text { Stage } \\
\text { IIIA } \\
\text { IIIB }\end{array}$ & $\begin{array}{l}19(51.4) \\
18(48.6)\end{array}$ & $\begin{array}{l}15(34.1) \\
29(65.9)\end{array}$ & 0.1 \\
\hline $\begin{array}{l}\text { Treatment response } \\
\text { stable } \\
\text { partial } \\
\text { complete } \\
\text { progression }\end{array}$ & $\begin{array}{l}7(20) \\
21(60) \\
3(8.6) \\
4(11.4)\end{array}$ & $\begin{array}{c}9(23.1) \\
20(51.3) \\
3(7.7) \\
7(17.9)\end{array}$ & 0.001 \\
\hline $\begin{array}{l}\text { Metastasis } \\
\text { local } \\
\text { distant }\end{array}$ & $\begin{array}{l}6(40) \\
9(60)\end{array}$ & $\begin{array}{l}5(71.4) \\
2(28.6)\end{array}$ & 0.01 \\
\hline
\end{tabular}



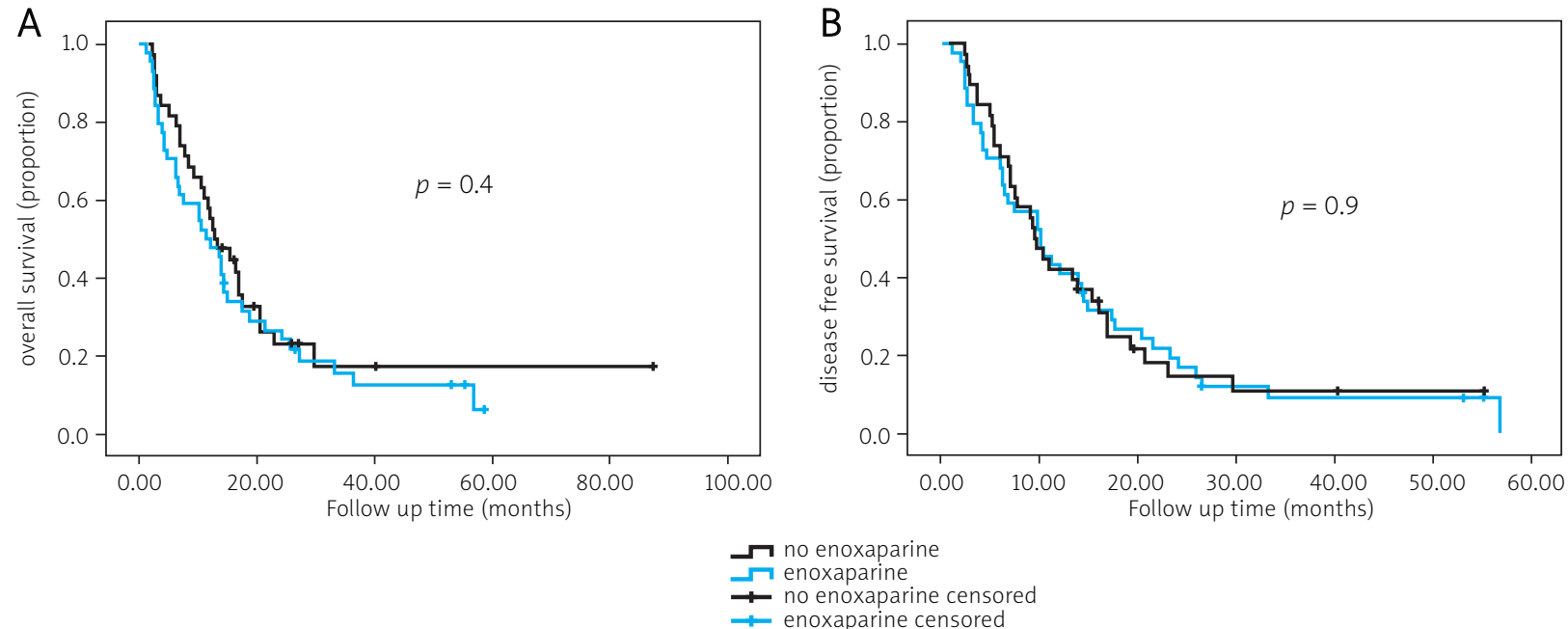

Fig. 1. Kaplan-Meier estimates of overall survival and disease free survival according to treament group

Table 2. Overview of survival data

\begin{tabular}{lcc} 
Variable & $\begin{array}{c}\text { Enoxaparin } \\
\text { Median months (range) }\end{array}$ & $\begin{array}{c}\text { No enoxaparin } \\
\text { Median months (range) }\end{array}$ \\
\hline Disease-free survival & $10(5.8-14.2)$ & $9.3(7.4-11.2)$ \\
Overall survival & $11.2(7.1-15.3)$ & $12.7(7.4-18.0)$
\end{tabular}

The patients were examined for the development of toxicity. Grade 3, 4 neutropenia was detected in 3 patients (7\%) in the CRT plus LMWH group and 6 patients (16.7\%) in the CRT-only group ( $p=0.3$ ). Grade 3, 4 mucositis and/or esophageal mucositis was detected in 5 patients (11.4\%) in the CRT plus LMWH group and 4 patients (10.5\%) in the CRT-only group ( $p=0.7$ ). One patient in the CRT plus LMWH group died as a result of hemoptysis. No deep vein thromboses developed in any patients.

\section{Discussion}

For stage IIIA and IIIB NSCLC, the survival rate is low in spite of aggressive treatments [16]. Stage III NSCLC affects a heterogeneous group of patients who are generally offered combined treatments including surgery and/or chemotherapy and/or radiotherapy. For patients with inoperable stage III NSCLC, the standard treatment is platinumbased chemotherapy with radiotherapy (CRT).

In cancer patients, thromboembolic complications are frequently observed. Anticoagulant treatments, especially LMWH, have been used to improve the survival in cancer patients with thromboembolic events. However, the effect of LMWH prophylaxis on cancer survival is controversial. There are some studies in the published literature reporting the antitumor activity of anticoagulant agents. These studies frequently focus on heparin, as an anticoagulant. Studies have demonstrated regression in the primary tumor [17, 18], as well as a reduced likelihood of developing metastases [19].

We observed a good clinical course in cancer patients using LMWH. Therefore, we noted in our retrospective study the positive effects of LMWH for cancer patients [20]. The aim of this study was to determine whether the addition of $\mathrm{LMWH}$ to CRT would improve NSCLC patient outcomes compared with CRT alone.

This study on the effects of the LMWH enoxaparin on the survival of patients with NSCLC and without other indications for anticoagulation demonstrated no overall survival advantage for those treated with enoxaparin. The median survival was 11.2 months among enoxaparin recipients, and 12.7 months among the non-enoxaparin group $(p=0.4)$. Even the median survival was better in the non-enoxaparin group. The low median survival time could be due to the larger number of patients with stage IIIB NSCLC in the enoxaparin group. However, DFS was better (10.0 vs. 9.3 months) for the enoxaparin group. In a randomized trial on the survival effects of LMWH for patients with stage IIIB NSCLC, the median survival was 12.1 months in the LMWH group and 10.3 months in the control group $(p=0.63)$ [13]. There were also other similar studies in the literature [21].

In our study, metastases were generally local rather than distant metastases in the LMWH group ( $p=0.01)$. The regression of NSCLC metastases after LMWH use has been reported in a study [22]. In the studies, heparin was used for a period one and three months, during chemotherapy $[13,18]$. In our study, heparin was used for one month during the CRT treatment period. Periods of LMWH use differ from study to study. If heparin use was prolonged, it could positively affect survival.

Consequently, no benefits of LMWH use were identified for patients with stage III NSCLC. However, the effect of LMWH on patient survival continues to be controversial.

The authors declare no conflict of interest. 


\section{References}

1. Manual of clinical oncology [Lippincott Manual Series (Spiral Manual Series)]. Casciato DA, Mary C. Territo (eds.). Lippincott Williams \& Wilkins, 2008; 169-87.

2. Detterbeck FC, Boffa DJ, Tanoue LT, Wilson LD. Details and difficulties regarding the new lung cancer staging system. Chest 2010; 137 1172-80.

3. Chansky K, Sculier JP, Crowley JJ, Giroux D, Van Meerbeeck J, Goldstraw P. The International Association for the study of Lung Cancer staging Project: prognostic factors and pathologic TNM stage in surgically managed non small cell lung cancer. J Thorac Oncol 2009; 4: 792-801.

4. Okawara G, Mackay JA, Evans WK, Ung YC; Lung Cancer Disease Site Group of Cancer Care Ontario's Program in Evidence-based Care. Management of unresected stage III non-small cell lung cancer: a systematic review. J Thorac Oncol 2006; 1: 377-93.

5. Engman CA, Zacharski LR. Low molecular weight heparins as extended prophylaxis against recurrent thrombosis in cancer patients. J Natl Compr Canc Netw 2008; 6: 637-45.

6. Hara N, Kotho H, Kuwano K. Cancer and thromboembolism. Nihon Rinsho 1999; 57: 1648-52.

7. Zacharski LR, Prandoni P, Monreal M. Warfarin versus low-molecular-weight heparin therapy in cancer patients. Oncologist 2005; 10: $72-9$

8. Owen CA Jr. Anticoagulant treatment of rats with Walker 256 carcinosarcoma. J Cancer Res Clin Oncol 1982; 104: 191-3.

9. Nagawa H, Paris P, Chauffert B, Martin F. Treatment of experimen tal liver metastases in the rat by continuous intraportal infusion of 5-fluorouracil and heparin: a pilot study. Anticancer Drugs 1990; 1: 149-56.

10. Prandoni P, Lensing AW, Büller HR, et al. Comparison of subcutaneous low-molecular-weight heparin with intravenous standard heparin in proximal deep-vein thrombosis. Lancet 1992; 339: 441-5.

11. Siragusa S, Cosmi B, Piovella F, Hirsh J, Ginsberg JS. Low-molecular-weight heparins and unfractionated heparin in the treatment of patients with acute venous thromboembolism: results of a meta-analysis. Am J Med 1996; 100: 269-77.

12. Zacharski LR, Henderson WG, Rickles FR, et al. Effect of warfarin anticoagulation on survival in carcinoma of the lung, colon, head and neck, and prostate. Final report of VA Cooperative Study 75. Cancer 1984; 53: 2046-52.

13. van Doormaal FF, Di Nisio M, Otten HM, Richel DJ, Prins M, Buller HR. Randomized trial of the effect of the low molecular weight heparin nadroparin on survival in patients with cancer. J Clin Oncol 2011; 29: 2071-6.

14. Tierney LM, Mcphee SJ, Papadakıs MA (eds.). Current medical diagnosis and treatment. McGraw Hill, New York 2008; 255.

15. $\mathrm{NCl}$ (National Cancer Institute) Common Toxicity Criteria Version. Version 2: ctep.cancer.gov.pdf.

16. Grunenwald DH. Surgery for locally advanced non-small cell lung cancer. Semin Surg Oncol 2003; 21: 85-90.

17. Elias EG, Shukla SK, Mink IB. Heparin and chemotherapy in the management of inoperable lung carcinoma. Cancer 1975; 36: 129-36.

18. Altinbas M, Coskun HS, Er O, et al. A randomized clinical trial of combination chemotherapy with and without low-molecular-weight heparin in small cell lung cancer. J Thromb Haemost 2004; 2 1266-71.

19. Lee AE, Rogers LA, Jeffery RE, Longcroft JM. Comparison of metastatic cell lines derived from a murine mammary tumor and reduction of metastasis by heparin. Clin Exp Metastasis 1988; 6: 463-71.

20. Zincircioglu SB, Kaplan MA, Isıkdogan A, et al. Contribution of lowmolecular weight heparin addition to concomitant chemoradiotherapy in the treatment of glioblastome multiforme. 35th ESMO Congress; 2010; 21: viii331.

21. Kakkar AK, Kadziola Z, Willamson RC, Levine MN, Low V, Lemoine NR. Low molecular weight heparin therapy and survival in advanced cancer. Blood 2002; 100: 557 (Abstract).

22. Loynes JT, Zacharski LR, Rigas JR. Regression of metastatic non-small cell lung cancer with low molecular weight heparin. Thromb Haemost 2002; 88: 686.

\section{Address for correspondence}

\section{Dr. Mehmet Kucukoner}

Medicine Faculty

Dicle Universty

Turkey

tel. + 9004122488001

fax +904122288523

e-mail: drmehmetonko@hotmail.com

Submitted: 22.01 .2012

Accepted: $\quad 31.07 .2012$ 